\title{
UTILIZING THE METABOLIC SYNDROME COMPONENT COUNT IN WORKERS' HEALTH SURVEILLANCE: AN EXAMPLE OF DAY-TIME VS. DAY-NIGHT ROTATING SHIFT WORKERS
}

YU-CHENG LIN ${ }^{1,2}$, I-CHUN HSIEH ${ }^{3}$, and PAU-CHUNG CHEN ${ }^{4}$

${ }^{1}$ En Chu Kong Hospital, New Taipei, Taiwan

Department of Occupational Medicine

${ }^{2}$ Fu Jen Catholic University, New Taipei, Taiwan

School of Medicine

${ }^{3}$ Taiwan Adventist Hospital, Taipei, Taiwan

Department of Environmental and Occupational Medicine

${ }^{4}$ National Taiwan University College of Public Health, Taipei, Taiwan

Institute of Occupational Medicine and Industrial Hygiene

\begin{abstract}
Objectives: To establish a practical method for assessing the general metabolic health conditions among different employee groups, this study utilized the total count of metabolic syndrome (MetS) elements as a parameter, and performed a retrospective analysis comparing changes of MetS component count (MSC) of 5 years among day-time work (DW) and day-andnight rotating shift work (RSW) employees. Material and Methods: The data of personal histories, physical examinations, blood tests, abdominal sonographic examinations and occupational records were collected from a cohort of workers in an electronics manufacturing company. We first defined the arithmetic mean value of MSC as MSC density (MSCD) for the employee group; then we compared the changes of MSCD over 5 years between DW and RSW workers. Occupational, personal and health records were analyzed for the 1077 workers with an initial mean age of 32.4 years (standard deviation (SD): 6.2 years), including 565 RSW workers (52\%). Results: The initial MSCDs were 1.26 and $1.12(\mathrm{p}=0.06)$ for DW and RSW workers, respectively; after 5 years, the increments of MSCD for DW and RSW workers were 0.10 and 0.39 , respectively $(\mathrm{p}<0.01)$. By performing multivariate logistic regression analyses, and comparing with DW co-workers, final results indicated that the workers exposed to RSW have 1.7-fold increased risk of elevated MSCD (95\% confidence interval (CI): 1.28-2.25, $\mathrm{p}<0.01$ ); and are 38\% less likely (adjusted rate ratio ( $\mathrm{aRR}) 0.62,95 \% \mathrm{CI}: 0.45-0.86, \mathrm{p}<0.01)$ to attain decreased MSCD. Conclusions: These observations demonstrate that changes of MSCD are significantly different between DW and RSW workers, and are increasingly associated with RSW exposure. In conclusion, MSCD can represent the general metabolic health conditions of a given employee group; MSC, MSCD and their transitional changes can be applied as simple and standardized tools for monitoring metabolic health risk profiles when managing employee health, at both the individual and company levels.
\end{abstract}

Key words:

Metabolic syndrome, Day-and-night rotating shift work, Occupational health, Physical examination

Received: May 22, 2014. Accepted: November 12, 2014.

Corresponding author: P.-C. Chen, National Taiwan University, College of Public Health, Institute of Occupational Medicine and Industrial Hygiene, Room 733, 17 Syujhou Road, Taipei 10055, Taiwan (e-mail: gphinx@gmail.com, pchen@ntu.edu.tw). 


\section{INTRODUCTION}

In 2013, an amendment of the Taiwan Occupational Safety and Health Act [1] required employers to adopt health management measures based on employees' health examination results to prevent work-related cardiovascular and cerebrovascular diseases. Yet, performing a proper health risk assessment can be a complicated and time-consuming process involving calculations and extrapolations from surveys of detailed health examination items [2].

In order to implement workplace health management in various workplaces, it is helpful to develop a simple, standardized and practical general metabolic health [3,4] risk assessment tool for different worksites. The count (from 0 to 5) of metabolic syndrome (MetS) [5,6] components [7-9] have been reported to be associated with a wide-range of risks of unfavorable health outcomes including cardiovascular, cerebrovascular diseases [2,10-12] and several malignancies [13,14], of which the risks rise in proportion to the count of MetS components.

In the interest of simplifying health managing processes and multi-functionalizing data from general health screening for health management in modern workplaces, we decided to investigate whether the records from a MetS screening program $[15,16]$ can be practically applied to the health risk assessment of different employee groups. Given that Taiwan's government legislation views shift work as an important health hazard [1] in workplaces, together with the fact that periodic routine health examinations [17] are compulsory for workers in Taiwan, we conducted a workplace-based retrospective follow-up study to evaluate the changes of MSC among workers with and without rotating shifts, an important occupational exposure.

\section{MATERIAL AND METHODS}

\section{Study populations}

On-site workers in 1 electronics manufacturing company received compulsory periodic health checkups to monitor general health conditions. The retrospective analysis of this cohort included only individuals who responded to work-status questionnaires and attended annual health examinations in both 2002 and 2007. The endpoint analysis included the records of 1077 workers, including $255 \mathrm{fe}$ males and 822 males. The health examinations were open to all registered employees on working days over a 1-month duration in any given year. Subjects' identities were anonymous and unlinked to the data. This analytical study followed the ethical criteria for human research; the study protocol (TYGH09702108) was reviewed and approved by the Ethics Committee of the Tao-Yuan General Hospital, Taiwan.

\section{Demographics, lifestyle data, job-type, biological measurements and sonogram examinations}

In 2002, baseline personal-history questionnaires that included questions about smoking habits, physical exercise, and dietary habits were completed by all participants. The types of job schedules, day-time work (DW) or dayand-night rotating shift work (RSW), were determined from self-reported questionnaires in 2002 and 2007. In 2002, a questionnaire about baseline personal history, including physical exercise, smoking and dietary habits, was completed by the examinees. Physical examinations and blood tests were performed in all participants in both 2002 and 2007.

The participants arrived at the health care unit of the factory in the morning 7:30-9:30 a.m., after an overnight $8 \mathrm{~h}$ fast. The physical examination records included measurements of waist circumference, weight, height, and blood pressure. Waist circumferences were measured midway between the lowest rib and the superior border of the iliac crest. After being seated for $5 \mathrm{~min}$, sitting blood pressure was measured on the dominant arm using digital automatic sphygmomanometers (model HEM 907, Omron, Japan) 2 times at 5-min intervals; the mean of the reading was used for data analysis. 
After the physical examination, participants were placed in a reclining position, and venous blood $(20 \mathrm{ml})$ from an antecubital vein of the arm was collected for subsequent tests. Blood specimens were centrifuged immediately thereafter and shipped frozen in dry ice to the central clinical laboratory (certified by ISO 15189 and ISO 17025) in TaoYuan General Hospital. Glucose, triglyceride, high-density lipoprotein (HDL) cholesterol, alanine aminotransferase (ALT), and uric acid analyses were conducted by a Hitachi autoanalyzer, model 7150 (Hitachi, Tokyo, Japan).

Since sonographic diagnosis for fatty liver has acceptable agreement among operators [18] and is widely accepted in many epidemiological surveys [19], this noninvasive method was used to diagnose fatty liver, an important risk factor of MetS [20]. In 2002, abdominal ultrasound examinations were performed for all examinees, using convex-type realtime electronic scanners (Toshiba SSA-340 with $3.75 \mathrm{MHz}$ convex-type transducer).

\section{Definitions}

Self-reported occupational risk factors

Information regarding the type of work schedule (RSW or DW) and basic personal data were collected from selfreported questionnaires in 2002 and 2007. Health examinations were given annually for workers in this company. Most employees of factories with automatic production lines are engaged in either light manual labor jobs or purely sedentary work.

Work schedules on the 24-h production line are based on a 3-team/2-shift plan: a repeating sequence of 6 daytime shifts followed by 3 off days, 6 night-time shifts, and then another 3 off days. The day-time and night-time shifts begin at 7:30 a.m. and 7:30 p.m., respectively. In the questionnaire employees indicated they had worked on a rotating shift for at least 1 year by responding "yes" to "I work on a rotating shift." Generally, this shift schedule is maintained in this type of factory unless family events or work promotions bring a change. Individuals not on rotating schedules for at least 1 year at the beginning and at the end of our follow-up were likely to have continued on with the same job description and day-time only work schedule. For these reasons, we divided work schedules into the following 2 categories:

- persistent DW rotating shift work not indicated in the records from 2002 and 2007,

- persistent RSW where rotating shift work was indicated in both records.

We excluded the data of intermittent shift workers (shift work indicated only in 2002 or only in 2007) from our final analysis to minimize the uncertainty of this occupational exposure.

We defined "having routine physical exercise" as, "doing exercise more than 3 times every week." To define "ever been a smoker," the 1st question was "Do you smoke?" (1. "Never," 2. "Currently smoke," 3. "Previously smoked, have since quit")," and this was followed by questions about frequency. We defined "ever been a smoker" as answering "yes" to question 2 or 3 and consuming at least 6 cigarettes daily for over 1 year. For defining "have the habit of snacking," the 1st questions were "Do you have the habit of snacking before sleeping?" and "Do you have the habit of snacking between meals?". These were followed with questions regarding quantity. We defined a "snacking habits" in the present study as snacking more than 3 times per week. The standard portions of examples for snacks (fruit products, milk products, fried food, nuts, beans products, meat, and alternatives) were explained to examinees in questionnaires.

\section{Metabolic syndrome}

Metabolic syndrome components were noted if the examinees had any following risk determinants:

- central obesity (COB - waist circumference more than $90 \mathrm{~cm}$ in men and $80 \mathrm{~cm}$ in women),

- high blood pressure (HBP - systolic blood pressure $(\mathrm{SBP}) \geq 130 \mathrm{~mm} \mathrm{Hg}$ or diastolic blood pressure (DBP) $\geq 85 \mathrm{~mm} \mathrm{Hg}$ ), 
- hyperglycemia (hyper-GL - fasting sugar $\geq 100 \mathrm{mg} / \mathrm{dl}$ ),

- hypertriglyceridemia (hyper-TG - triglycerides $\geq 150 \mathrm{mg} / \mathrm{dl}$ ),

- low-HDLcholesterolemia (low-HDL-HDL < $40 \mathrm{mg} / \mathrm{dl}$ in men and $<50 \mathrm{mg} / \mathrm{dl}$ in women) [21].

We specified the MetS component count (MSC) as a summation of the numbers of MetS 5 components for an individual or a worker group, and the arithmetic mean value of MSC for a worker group was defined as MSC density (MSCD).

Sonographic fatty liver was assessed using the following 5 parameters: liver-kidney contrast, gall bladder wall masking, blurring of wall of hepatic and portal veins and far attenuation of the diaphragm. Diagnosis was made according to previous reports [22].

\section{Statistical analysis}

Baseline characteristics and abnormal rates were compared between DW and RSW workers within 5 years using the t-test and the $\mathrm{Chi}^{2}$ test for categorical and continual variables as appropriate. Multivariate logistic regression was used to estimate the adjusted rate ratio (aRR), and $95 \%$ confidence intervals (CI) of risk factors were used for predicting increased or decreased MSCD, after adjusting for gender, initial age, each MetS component, uric acid, alanine aminotransferase, sonographic fatty liver and occupational and lifestyle factors [23,24]. A p-value $<0.05$ was considered statistically significant.

\section{RESULTS}

Records were analyzed for 1077 employees with an average term of employment of 7.7 years ( $\mathrm{SD}=5.7$ years) and an initial mean age of 32.4 years ( $\mathrm{SD}=6.2$ years). Table 1 summarizes data in 2002 obtained from the baseline health check-ups and personal and occupational records of 255 female and 822 male workers. There were 565 employees (52\%) engaged in RSW during this 5-year follow-up.
Insignificant differences in measurements of general health conditions were found between female DW and RSW workers, with the exception that RSW workers showed higher diastolic blood pressure, higher rates of having snacks before sleeping, smoking and a lower rate of physical exercise at the baseline survey.

Among male workers, RSW workers were significantly younger, thinner and had more favorable blood test results for sugar and lipids and lower abnormality rates of sonographic fatty liver, while having higher rates of snacks before sleeping, smoking and a lower rate of physical exercise than did their DW co-workers.

Table 2 presents abnormality rates of individual MetS components among the total sample population, female and male workers at baseline in 2002 and at endpoint in 2007. The changes of MSCD between the DW and RSW workers are also shown in Table 2. The initial abnormality rates of each MetS component were significantly unfavorable for the DW workers (DW vs. RSW workers: hyper-GL: $32.8 \%$ vs. $25.1 \%$, p < 0.01; low-HDL: $34.4 \%$ vs. $28 \%, \mathrm{p}=0.02)$. Similar abnormality rates of MetS components existed between female DW and RSW workers, with the exception that RSW workers showed a higher rate of HBP (DW vs. RSW workers: 9.5\% vs. 18.6\%, p < 0.01). Among male workers, the initial abnormality rates of each MetS component were also significantly unfavorable for the DW workers (hyper-GL: $34.7 \%$ vs. $25.3 \%, \mathrm{p}<0.01$; hyper-TG: $32 \%$ vs. $24.4 \%, \mathrm{p}=0.02$; low-HDL: $32 \%$ vs. $25.7 \%, \mathrm{p}=0.05$; DW vs. RSW workers).

In 2007, none of the abnormality rates of MetS components except HBP were significantly different between DW and RSW workers. Table 2 also shows the significant 5-year changes of MCSD between DW and RSW workers for the total population: 0.10 vs. $0.39, \mathrm{p}<0.01$; female workers: -0.10 vs. $0.29, \mathrm{p}<0.01$; and male workers: 0.17 vs. $0.41, p<0.01$ (Table 2 , the lowest rows).

Details of the prevalence rates of increased and decreased MSC among the total, female and male worker 


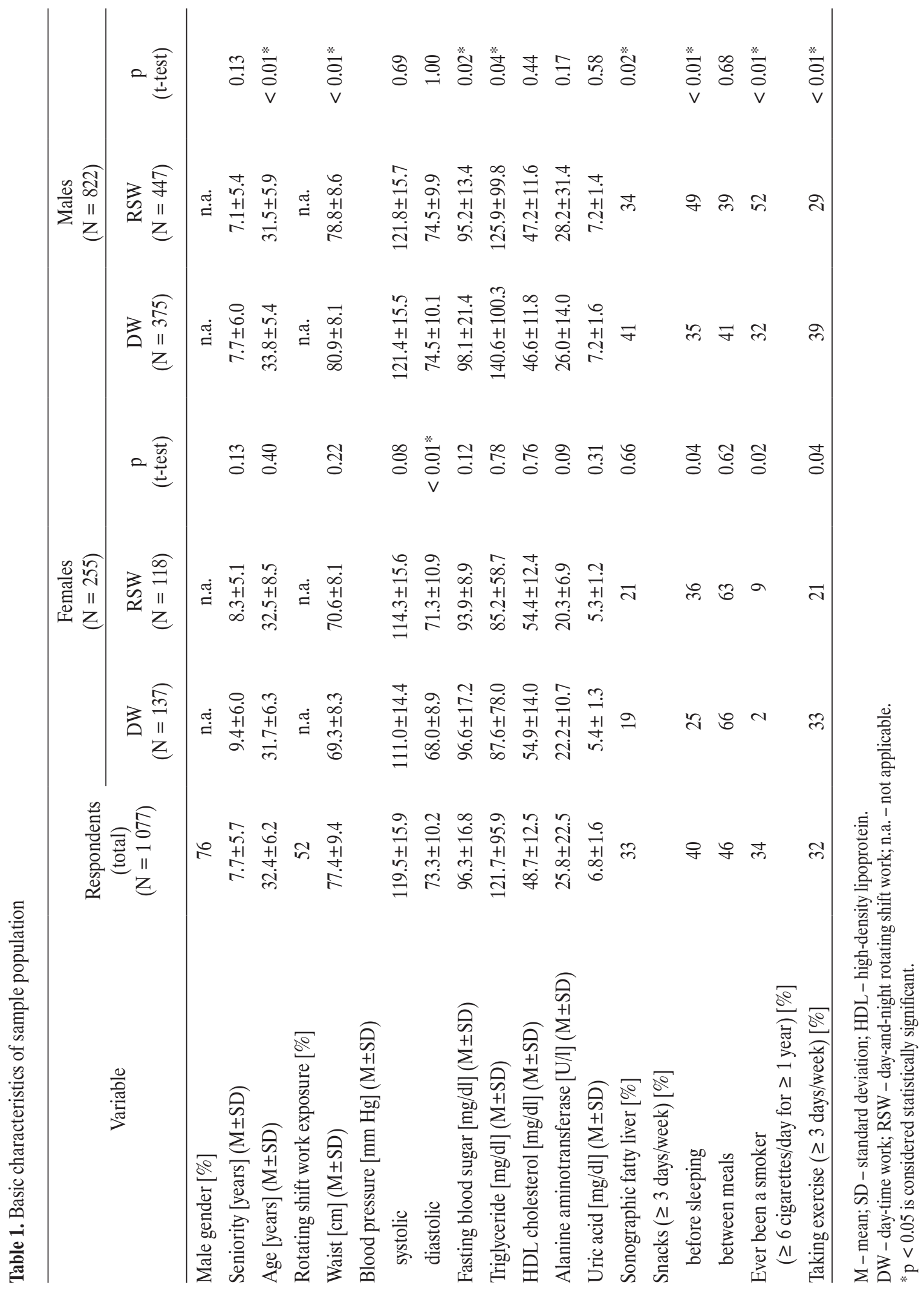




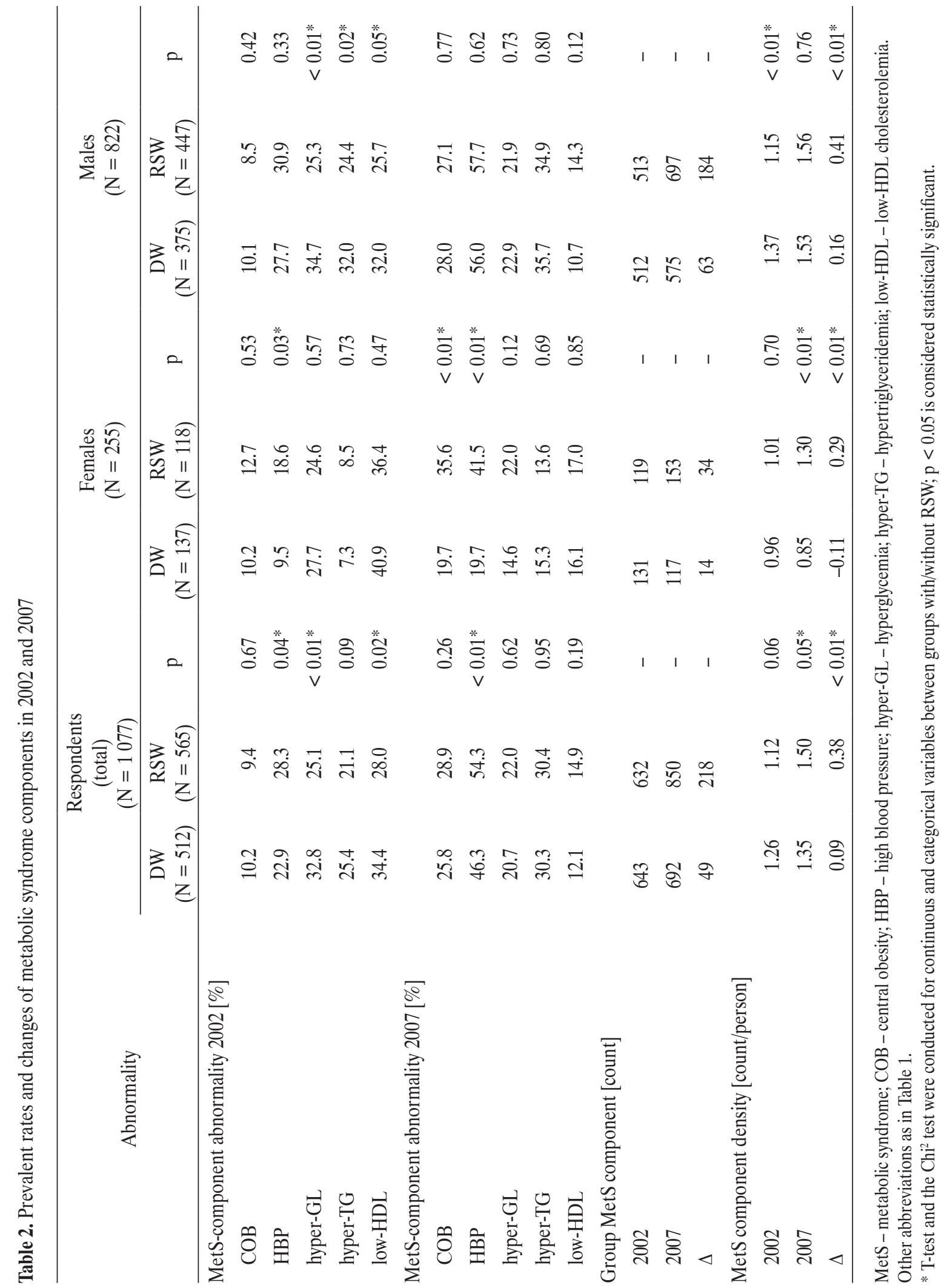



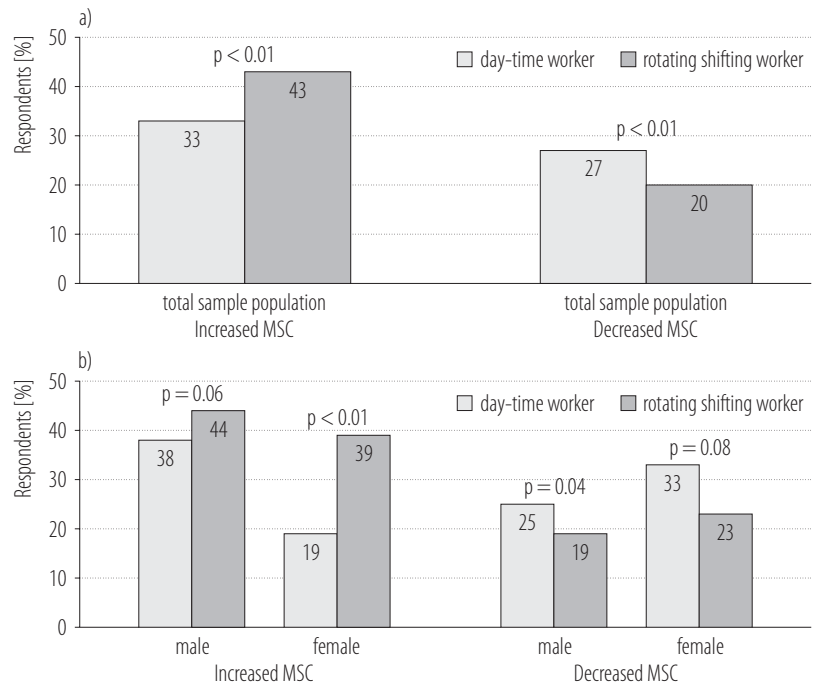

$\mathrm{P}$ value is result of $\mathrm{Chi}^{2}$ test.

DW - day-time work; RSW - day-and-night rotating shift work.

Fig. 1. Prevalence rates of increased and decreased metabolic syndrome component count (MSC) among a) total sample population and b) each gender

subgroups are shown in Figure 1. Similarly, in the total, female and male worker populations, RSW employees had significantly higher rates of increased MSC and lower rates of reduced MSC than did their DW co-workers.

Table 3 shows the adjusted RRs for increased and decreased MSCs among worker groups. After controlling for confounding factors (age, occupational factors, lifestyle, MetS components, liver enzyme, uric acid abnormality and sonographic fatty liver), multivariate analysis indicated that the workers exposed to RSW had a 1.7-fold higher risk for increased MSCD (95\% CI: 1.28-2.25, p < 0.01) and were 38\% less likely (aRR: $0.62,95 \%$ CI: $0.45-0.86, p<0.01$ ) to attain decreased MSCD within this 5-year interval. Similarly, among female and male workers, female RSW workers had a 2.1-fold higher risk for increased MSCD (95\% CI: 1.06-4.15, p = 0.03) and were $51 \%$ less likely (aRR: $0.49,95 \%$ CI: $0.25-0.96$, $\mathrm{p}=0.04)$ to attain decreased MSCD; male RSW workers had a 1.5-fold increased risk for elevated MSCD $(95 \% \mathrm{CI}$ : 1.12-2.12, $\mathrm{p}<0.01$ ) and were $33 \%$ less likely (aRR: 0.67 , 95\% CI: $0.46-0.99, p=0.05)$ to attain decreased MSCD.

\section{DISCUSSION}

Conventionally, MetS is a good risk predictor of cardiocerebrovascular disease for an individual. In the present study, in epidemiological terms, we demonstrate that the changes of MSCD, much simpler than other complicated evaluating index [2], are significantly different among workers with or without a specific occupational exposure.

Many credible studies have closely linked MSC with various unfavorable health outcomes of the whole human body, including malignancies [13,14], cardiovascular diseases [25,26], cognitive impairment [27], respiratory diseases [12,28], kidney diseases [29,30], insulin resistance [7,31], diabetes mellitus [8,11], increased oxidative stress [32,33], inflammatory reactions $[34,35]$ as well as mutations on genetic levels [36-38], of which the risks rise proportionally associated with MSC.

In accordance with our findings and the above mentioned epidemiological observations, and since all the standardized measurements of MetS elements are accessible in most medical settings [39], MSC, MSCD and their changes can serve as basic and practical parameters for evaluating the general health conditions of employees in various workplaces.

In terms of occupational exposure, our observations support the previous studies highlighting the potentially worrying effects of night shift work schedules on employee health $[15,40-45]$. We demonstrate that even though that the RSW workers were significantly younger, thinner, and had a lower prevalence rate of preexisting health abnormalities than their coworkers involved in DW works (Table 1) at baseline, they showed increased MSC, and lower presence of decreased MSC (Table 2 and 3, Figure 1) after 5 years. Circadian disruption has been linked with premature aging process [46], high blood pressure [47], obesity [48], abnormal blood lipids and sugar [49,50]. We recommend every risk factor of MetS should be managed among workers; furthermore, with the knowledge 
Table 3. Adjusted rate ratio for the increased and decreased metabolic syndrome component densities among employee groups

\begin{tabular}{|c|c|c|c|c|c|c|}
\hline \multirow{2}{*}{ Respondents } & \multicolumn{3}{|c|}{ Increased MetS component count } & \multicolumn{3}{|c|}{ Decreased MetS component count } \\
\hline & aRR & $95 \% \mathrm{CI}$ & $\mathrm{p}$ & aRR & $95 \% \mathrm{CI}$ & $\mathrm{p}$ \\
\hline \multicolumn{7}{|l|}{ Total } \\
\hline male vs. female & 1.58 & $1.04-2.41$ & 0.03 & 0.31 & $0.19-0.50$ & $<0.010$ \\
\hline RSW vs. DW & 1.70 & $1.28-2.25$ & $<0.01$ & 0.62 & $0.45-0.86$ & $<0.010$ \\
\hline \multicolumn{7}{|l|}{ Female employee } \\
\hline RSW vs. DW & 2.10 & $1.06-4.15$ & 0.03 & 0.49 & $0.25-0.96$ & 0.040 \\
\hline \multicolumn{7}{|l|}{ Male employee } \\
\hline RSW vs. DW & 1.54 & $1.12-2.12$ & $<0.01$ & 0.67 & $0.46-0.99$ & 0.046 \\
\hline
\end{tabular}

aRR - rate ratio adjusted for gender, initial age, each MetS component, uric acid abnormality, elevated liver enzymes, sonographic fatty liver, occupational and lifestyle factors including snacking, smoking and exercising.

Other abbreviations as in Table 1.

of MSCD increasing among RSW workers, thorough health promotion efforts are needed, particularly for shift workers.

Comparing the gender differences of MetS component abnormalities among these worker populations, our findings are similar to those of many previous large-scale studies [15,51], which show that male workers have higher risk of developing MetS-related abnormalities than do female workers (Table 3). Sex-specific [52] risk predictors should be considered in primary prevention for incidence of MetS in workplaces.

Each component of MetS intervention has independent goals to be achieved, while no single effective pharmacological treatment simultaneously affecting all components of MetS equally has yet been found. Worksite health promotion programs for MetS have been reported to achieve substantial risk reduction $[53,54]$.

Prevention and treatment [55] of the predictive factors together with enhanced lifestyle-modification [56,57] and intervention [58] may jointly reduce the prevalence of MetS risk factors [59]. A good example of significant decreases in MSC (from 2.1 down to 1.1) can be found in a study of subjects who completed a weight loss program [60]; similarly, for many health conditions, it is worthwhile to put greater efforts into addressing obesity [61]. On the other hand, dietary therapies, such as salt restriction [51] or increased fiber consumption [54], are essential for reducing MSC in subjects with risk factors [62]. For shift workers, due to the complex nature of gene-nutritionenvironment interactions [63-65], MetS treatments including dietary adjustment may require a personalized approach [66-69].

In addition to the aspects of employees' health, elevated MSC is associated with increased medical costs [70,71]. Milani et al. reports decreased total health risk and markedly reduced medical claim costs through worksite health programs [72]. Whether RSW significantly inflates economic burden in workplaces in Taiwan, and whether reductions of MSCD lower medical costs among workers are interesting issues for further investigation.

This is the 1st large-scale observational research utilizing MSC, MSCD and their changes to evaluate general health conditions among workers. The conclusions drawn from our observations of a stable, relatively young and healthy worker population may benefit employees in similar workplaces. However, retrospective epidemiological surveys are fundamentally not as compelling as prospective investigations in the identification of causal 
associations; hence, some potential limitations of our analysis need to be considered.

At the commencement of this study, the elder male DW had a significantly larger MSCD than the younger RSW did. However, after 5 years, MSCDs became similar between male DW and RSW workers. Aging process might partially explain the higher MSCD of DW than RSW at baseline. The specific comparisons between DW and RSW at baseline may involve a future prospective study for a cohort who developed MS from the baseline of 0 MSC. In addition, since we did not obtain the accurate chemical exposure data and information of sleep quality, we cannot derive the health effects from chemical exposures and sleep quality here. Future studies need to take these potential confounders of MetS development into consideration.

Due to the convenient, comprehensive medical care in Taiwan, one limitation of this investigation is that we did not consider potential protective effects [73-76] of treatment among workers with abnormal MetS components over the 5-year study interval. Thus, we may have underrated the risk of shift work for increased risk of each MetS component. Additionally, this is a workplace follow-up survey for relatively healthy workers. Therefore, the application of our conclusions to the general population should be a conservative one.

\section{CONCLUSIONS}

Metabolic syndrome component count density can potentially be a good indicator of the general metabolic health conditions of a given group of workers. To practically satisfy the legal requirements of managing employees' health, we suggest using MSC and MSCD as a simple tool for general metabolic health assessments in various workplaces.

\section{ACKNOWLEDGMENTS}

The authors would like to acknowledge the personnel of the Center of Health Management, Tao-Yuan General Hospital for their full support and generous assistance.

\section{REFERENCES}

1. Occupational Safety and Health Act, Article 6. Laws and Regulations Database of The Republic of China (Jul 3, 2013) [cited 2014 May 6]. Available from: http://laws.mol.gov.tw/ Eng/FLAW/FLAWDOC01.asp?Isid=FL015013\&lno $=6$.

2. Liu YM, Chen SL, Yen AM, Chen HH. Individual risk prediction model for incident cardiovascular disease: A Bayesian clinical reasoning approach. Int J Cardiol. 2013;167: 2008-12, http://dx.doi.org/10.1016/j.ijcard.2012.05.016.

3. Jung HS, Chang Y, Eun Yun K, Kim CW, Choi ES, Kwon MJ, et al. Impact of body mass index, metabolic health and weight change on incident diabetes in a Korean population. Obesity (Silver Spring). 2014;22:1880-7, http://dx.doi. org/10.1002/oby.20751.

4. Janssen I, Katzmarzyk PT, Ross R. Duration of overweight and metabolic health risk in American men and women. Ann Epidemiol. 2004;14:585-91, http://dx.doi.org/10.1016/ j.annepidem.2004.01.007.

5. Vyas MV, Garg AX, Iansavichus AV, Costella J, Donner A, Laugsand LE, et al. Shift work and vascular events: Systematic review and meta-analysis. BMJ. 2012;345:e4800.

6. Dusseault-Belanger F, Cohen AA, Hivert MF, Courteau J, Vanasse A. Validating metabolic syndrome through principal component analysis in a medically diverse, realistic cohort. Metab Syndr Relat Disord. 2013;11:21-8, http://dx.doi. org/10.1089/met.2012.0094.

7. Vaidya D, Szklo M, Liu K, Schreiner PJ, Bertoni AG, Ouyang P. Defining the metabolic syndrome construct: MultiEthnic Study of Atherosclerosis (MESA) cross-sectional analysis. Diabetes Care. 2007;30:2086-90, http://dx.doi.org/ $10.2337 / \mathrm{dc} 07-0147$.

8. Nichols GA, Moler EJ. Diabetes incidence for all possible combinations of metabolic syndrome components. Diabetes Res Clin Pract. 2010;90:115-21, http://dx.doi.org/10.1016/ j.diabres.2010.06.011.

9. Fekedulegn D, Andrew M, Violanti J, Hartley T, Charles L, Burchfiel C. Comparison of statistical approaches to evaluate factors associated with metabolic syndrome. J Clin Hypertens 
(Greenwich). 2010;12:365-73, http://dx.doi.org/10.1111/ j.1751-7176.2010.00264.x.

10. Takashima H, Ozaki Y, Morimoto T, Kimura T, Hiro T, Miyauchi K, et al. Clustering of metabolic syndrome components attenuates coronary plaque regression during intensive statin therapy in patients with acute coronary syndrome: The JAPAN-ACS subanalysis study. Circ J. 2012; 76:2840-7, http://dx.doi.org/10.1253/circj.CJ-11-1495.

11. Khang YH, Cho SI, Kim HR. Risks for cardiovascular disease, stroke, ischaemic heart disease, and diabetes mellitus associated with the metabolic syndrome using the new harmonised definition: Findings from nationally representative longitudinal data from an Asian population. Atherosclerosis. 2010;213:579-85, http://dx.doi.org/10.1016/j.atherosclerosis.2010.09.009.

12. Lin QC, Chen LD, Yu YH, Liu KX, Gao SY. Obstructive sleep apnea syndrome is associated with metabolic syndrome and inflammation. Eur Arch Otorhinolaryngol. 2014; 271:825-31, http://dx.doi.org/10.1007/s00405-013-2669-8.

13. Esposito K, Chiodini P, Capuano A, Bellastella G, Maiorino MI, Rafaniello $\mathrm{C}$, et al. Colorectal cancer association with metabolic syndrome and its components: A systematic review with meta-analysis. Endocrine. 2013;44:634-47, http://dx.doi.org/10.1007/s12020-013-9939-5.

14. Bhindi B, Locke J, Alibhai SM, Kulkarni GS, Margel DS, Hamilton RJ, et al. Dissecting the association between metabolic syndrome and prostate cancer risk: Analysis of a large clinical cohort. Eur Urol. 2015;67:64-70, http://dx.doi. org/10.1016/j.eururo.2014.01.040.

15. Kawabe Y, Nakamura Y, Kikuchi S, Murakami Y, Tanaka T, Takebayashi T, et al. Relationship between shift work and clustering of the metabolic syndrome diagnostic components. J Atheroscler Thromb. 2014;21:703-11, http://dx.doi. org/10.5551/jat.19380.

16. Lin YC, Chen JD, Lo SH, Chen PC. Worksite health screening programs for predicting the development of metabolic syndrome in middle-aged employees: A five-year follow-up study. BMC Public Health. 2010;10:747.
17. Occupational Safety and Health Act, Article 20. Laws and Regulations Database of the Republic of China (Jul 3, 2013) [cited 2014 May 6]. Available from: http://laws.mol.gov.tw/ Eng/FLAW/FLAWDOC01.asp?lsid=FL015013\&lno=20.

18. Strauss S, Gavish E, Gottlieb P, Katsnelson L. Interobserver and intraobserver variability in the sonographic assessment of fatty liver. AJR Am J Roentgenol. 2007;189:W320-3.

19. Mishra P, Younossi ZM. Abdominal ultrasound for diagnosis of nonalcoholic fatty liver disease (NAFLD). Am J Gastroenterol. 2007;102:2716-7, http://dx.doi.org/10.1111/j.15720241.2007.01520.x.

20. Chang TY, Chen JD. Fatty liver and metabolic syndrome in nonabdominally obese Taiwanese adults. Asia Pac J Public Health. 2012;24:472-9, http://dx.doi.org/10. 1177/1010539511402191.

21. Hsu PF, Chuang SY, Cheng HM, Tsai ST, Chou P, Chen CH. Clinical significance of the metabolic syndrome in the absence of established hypertension and diabetes: A community-based study. Diabetes Res Clin Pract. 2008;79:461-7, http://dx.doi.org/10.1016/j.diabres.2007.09.021.

22. Lin YC, Lo HM, Chen JD. Sonographic fatty liver, overweight and ischemic heart disease. World J Gastroenterol. 2005;11:4838-42.

23. Liu Y, Wheaton AG, Chapman DP, Croft JB. Sleep duration and chronic diseases among U.S. adults age 45 years and older: Evidence from the 2010 Behavioral Risk Factor Surveillance System. Sleep. 2013;36:1421-7.

24. Yang J, Teehan D, Farioli A, Baur DM, Smith D, Kales SN. Sudden cardiac death among firefighters $\leq 45$ years of age in the United States. Am J Cardiol. 2013;112:1962-7, http:// dx.doi.org/10.1016/j.amjcard.2013.08.029.

25. Lee YH, Shin MH, Kweon SS, Nam HS, Park KS, Choi JS, et al. Normative and mean carotid intima-media thickness values according to metabolic syndrome in Koreans: The Namwon Study. Atherosclerosis. 2014;234:230-6, http://dx.doi.org/10.1016/j.atherosclerosis.2014.02.023.

26. Knuiman MW, Hung J, Divitini ML, Davis TM, Beilby JP. Utility of the metabolic syndrome and its components in 
the prediction of incident cardiovascular disease: A prospective cohort study. Eur J Cardiovasc Prev Rehabil. 2009;16: 235-41, http://dx.doi.org/10.1097/HJR.0b013e32832955fc.

27. Yaffe K, Weston AL, Blackwell T, Krueger KA. The metabolic syndrome and development of cognitive impairment among older women. Arch Neurol. 2009;66:324-8.

28. Bae MS, Han JH, Kim JH, Kim YJ, Lee KJ, Kwon KY. The relationship between metabolic syndrome and pulmonary function. Korean J Fam Med. 2012;33:70-8, http:// dx.doi.org/10.4082/kjfm.2012.33.2.70.

29. Lerman LO, Lerman A. [The metabolic syndrome and early kidney disease: Another link in the chain?]. Rev Esp Cardiol. 2011;64:358-60, http://dx.doi.org/10.1016/ j.rec.2011.01.005. Spanish.

30. Gimeno-Orna JA, Molinero-Herguedas E, Lou-Arnal LM, Boned-Juliani B, Labrador-Fuster T, Guiu-Campos M. [Microalbuminuria accounts for the increased vascular disease risk in diabetic patients with metabolic syndrome]. Rev Esp Cardiol. 2007;60:1202-5, http://dx.doi.org/10.1016/ S1885-5857(08)60059-6. Spanish.

31. Verhagen SN, Wassink AM, van der Graaf Y, Gorter PM, Visseren FL; Group SS. Insulin resistance increases the occurrence of new cardiovascular events in patients with manifest arterial disease without known diabetes. The SMART study. Cardiovasc Diabetol. 2011;10:100, http://dx.doi.org/ 10.1186/1475-2840-10-100.

32. Sanchez-Rodriguez MA, Martinez-Cruz M, Correa-Munoz E, Mendoza-Nunez VM. Relationship between metabolic syndrome components and oxidative stress in elderly community-dwelling Mexicans. Ann Nutr Metab. 2010;56: 302-7, http://dx.doi.org/10.1159/000309601.

33. Kotani K, Yamada T. Oxidative stress and metabolic syndrome in a Japanese female population. Australas J Ageing. 2012;31:124-7, http://dx.doi.org/10.1111/j.1741-6612. 2011.00571.x.

34. Sung KC, Rhee EJ, Kim H, Park JB, Kim YK, Rosenson RS. Prevalence of low LDL-cholesterol levels and elevated highsensitivity C-reactive protein levels in apparently healthy
Korean adults. Nutr Metab Cardiovasc Dis. 2012;22:1061-6, http://dx.doi.org/10.1016/j.numecd.2011.03.006.

35. He CT, Lee CH, Hsieh CH, Hsiao FC, Kuo P, Chu NF, et al. Soluble form of receptor for advanced glycation end products is associated with obesity and metabolic syndrome in adolescents. Int J Endocrinol 2014;2014:657607, http://dx. doi.org/10.1155/2014/657607.

36. Huang CH, Su SL, Hsieh MC, Cheng WL, Chang CC, $\mathrm{Wu} \mathrm{HL}$, et al. Depleted leukocyte mitochondrial DNA copy number in metabolic syndrome. J Atheroscler Thromb. 2011;18:867-73, http://dx.doi.org/10.5551/jat.8698.

37. Hulsmans M, Sinnaeve P, van der Schueren B, Mathieu C, Janssens S, Holvoet P. Decreased miR-181a expression in monocytes of obese patients is associated with the occurrence of metabolic syndrome and coronary artery disease. J Clin Endocrinol Metab. 2012;97:e1213-8, http:/ dx.doi.org/10.1210/jc.2012-1008.

38. Luttmer R, Spijkerman AM, Kok RM, Jakobs C, Blom HJ, Serne EH, et al. Metabolic syndrome components are associated with DNA hypomethylation. Obes Res Clin Pract. 2013;7:e106-15.

39. Van den Hooven C, Ploemacher J, Godwin M. Metabolic syndrome in a family practice population: Prevalence and clinical characteristics. Can Fam Physician. 2006;52:982-3.

40. Karlsson B, Knutsson A, Lindahl B. Is there an association between shift work and having a metabolic syndrome? Results from a population based study of 27,485 people. Occup Environ Med. 2001;58:747-52, http://dx.doi.org/10.11 36/oem.58.11.747.

41. Puttonen S, Viitasalo K, Harma M. The relationship between current and former shift work and the metabolic syndrome. Scand J Work Environ Health. 2012;38:343-8, http:/ dx.doi.org/10.5271/sjweh.3267.

42. Mohebbi I, Shateri K, Seyedmohammadzad M. The relationship between working schedule patterns and the markers of the metabolic syndrome: Comparison of shift workers with day workers. Int J Occup Med Environ Health. 2012;25: 383-91, http://dx.doi.org/10.2478/s13382-012-0051-5. 
43. Pietroiusti A, Neri A, Somma G, Coppeta L, Iavicoli I, Bergamaschi A, et al. Incidence of metabolic syndrome among night-shift healthcare workers. Occup Environ Med. 2010;67:54-7, http://dx.doi.org/10.1136/oem. 2009.046797.

44. Wirth MD, Burch J, Shivappa N, Violanti JM, Burchfiel CM, Fekedulegn D, et al. Association of a dietary inflammatory index with inflammatory indices and metabolic syndrome among police officers. J Occup Environ Med. 2014;56:986-9, http://dx.doi.org/10.1097/JOM.0000000000000213.

45. Tucker P, Marquie JC, Folkard S, Ansiau D, Esquirol Y. Shiftwork and metabolic dysfunction. Chronobiol Int. 2012;29:549-55, http://dx.doi.org/10.3109/07420528.201 2.675259 .

46. Anisimov VN, Vinogradova IA, Panchenko AV, Popovich IG, Zabezhinski MA. Light-at-night-induced circadian disruption, cancer and aging. Curr Aging Sci. 2012;5:170-7, http://dx.doi.org/10.2174/1874609811205030002.

47. Su TC, Lin LY, Baker D, Schnall PL, Chen MF, Hwang WC, et al. Elevated blood pressure, decreased heart rate variability and incomplete blood pressure recovery after a 12-hour night shift work. J Occup Health. 2008;50:380-6, http://dx.doi.org/10.1539/joh.L7056.

48. Kim MJ, Son KH, Park HY, Choi DJ, Yoon $\mathrm{CH}$, Lee HY, et al. Association between shift work and obesity among female nurses: Korean Nurses' Survey. BMC Public Health. 2013;13:1204, http://dx.doi.org/10.1186/1471-245813-1204.

49. Szantoova K, Zeman M, Vesela A, Herichova I. Effect of phase delay lighting rotation schedule on daily expression of per2, bmal1, rev-erbalpha, pparalpha, and pdk4 genes in the heart and liver of Wistar rats. Mol Cell Biochem. 2011;348:53-60, http://dx.doi.org/10.1007/s11010-0100636-x.

50. Barclay JL, Husse J, Bode B, Naujokat N, Meyer-Kovac J, Schmid SM, et al. Circadian desynchrony promotes metabolic disruption in a mouse model of shiftwork. PLoS One. 2012;7:e37150.
51. Rhee MY, Kim JH, Kim YS, Chung JW, Bae JH, Nah DY, et al. High sodium intake in women with metabolic syndrome. Korean Circ J. 2014;44:30-6, http://dx.doi. org/10.4070/kcj.2014.44.1.30.

52. Park E, Kim J. Gender- and age-specific prevalence of metabolic syndrome among Korean adults: Analysis of the Fifth Korean National Health and Nutrition Examination Survey. J Cardiovasc Nurs. 2015;30:256-66, http://dx.doi. org/10.1097/JCN.0000000000000142.

53. Prabhakaran D, Jeemon P, Goenka S, Lakshmy R, Thankappan KR, Ahmed F, et al. Impact of a worksite intervention program on cardiovascular risk factors: A demonstration project in an Indian industrial population. J Am Coll Cardiol. 2009;53:1718-28.

54. Inoue H, Sasaki R, Aiso I, Kuwano T. Short-term intake of a Japanese-style healthy lunch menu contributes to prevention and/or improvement in metabolic syndrome among middleaged men: A non-randomized controlled trial. Lipids Health Dis. 2014;13:57, http://dx.doi.org/10.1186/1476-511X-13-57.

55. Altabas V. Drug treatment of metabolic syndrome. Curr Clin Pharmacol. 2013;8:224-31.

56. Lee EG, Choi JH, Kim KE, Kim JH. Effects of a walking program on self-management and risk factors of metabolic syndrome in older Korean adults. J Phys Ther Sci. 2014;26: 105-9, http://dx.doi.org/10.1589/jpts.26.105.

57. Yamaoka K, Tango T. Effects of lifestyle modification on metabolic syndrome: A systematic review and meta-analysis. BMC Med. 2012;10:138, http://dx.doi.org/10.1186/17417015-10-138.

58. Buscemi S, Sprini D, Grosso G, Galvano F, Nicolucci A, Lucisano $\mathrm{G}$, et al. Impact of lifestyle on metabolic syndrome in apparently healthy people. Eat Weight Disord. 2014;19: 225-32, http://dx.doi.org/10.1007/s40519-014-0117-4.

59. Pemminati S, Prabha Adhikari MR, Pathak R, Pai MR. Prevalence of metabolic syndrome (METS) using IDF 2005 guidelines in a semi urban south Indian (Boloor Diabetes Study) population of Mangalore. J Assoc Physicians India. 2010;58:674-7. 
60. Matsuo T, Murotake Y, Nakata Y, Seino S, Okura T, Tanaka K. [Effects of a community-based weight loss program, jointly established by local government and university faculty, on weight loss and metabolic syndrome components: The Sodegaura Weight Management Study]. Nihon Koshu Eisei Zasshi. 2010;57:390-402. Japanese.

61. Lin JD, Lin LP, Liou SW, Chen YC, Hsu SW, Liu CT. Gender differences in the prevalence of metabolic syndrome and its components among adults with disabilities based on a community health check up data. Res Dev Disabil. 2013; 34:516-20, http://dx.doi.org/10.1016/j.ridd.2012.09.001.

62. Otsuka R, Imai T, Kato Y, Ando F, Shimokata H. Relationship between number of metabolic syndrome components and dietary factors in middle-aged and elderly Japanese subjects. Hypertens Res. 2010;33:548-54, http://dx.doi. org $/ 10.1038 / \mathrm{hr} .2010 .29$.

63. Zamora-Valdes D, Mendez-Sanchez N. Experimental evidence of obstructive sleep apnea syndrome as a second hit accomplice in nonalcoholic steatohepatitis pathogenesis. Ann Hepatol. 2007;6:281-3.

64. Sharifian A, Farahani S, Pasalar P, Gharavi M, Aminian O. Shift work as an oxidative stressor. J Circadian Rhythms. 2005;3:15， http://dx.doi.org/10.1186/1740-339 1-3-15.

65. Puttonen S, Viitasalo K, Harma M. Effect of shiftwork on systemic markers of inflammation. Chronobiol Int. 2011;28:528-35, http://dx.doi.org/10.3109/07420528.201 1.580869 .

66. Lowden A, Moreno C, Holmback U, Lennernas M, Tucker P. Eating and shift work - Effects on habits, metabolism and performance. Scand J Work Environ Health. 2010;36:15062, http://dx.doi.org/10.5271/sjweh.2898.

67. Garcia-Rios A, Gomez-Delgado FJ, Garaulet M, AlcalaDiaz JF, Delgado-Lista FJ, Marin C, et al. Beneficial effect of CLOCK gene polymorphism rs1801260 in combination with low-fat diet on insulin metabolism in the patients with metabolic syndrome. Chronobiol Int. 2014;31:401-8, http:// dx.doi.org/10.3109/07420528.2013.864300.
68. De la Iglesia R, Lopez-Legarrea P, Abete I, Bondia-Pons I, Navas-Carretero S, Forga L, et al. A new dietary strategy for long-term treatment of the metabolic syndrome is compared with the American Heart Association (AHA) guidelines: The MEtabolic Syndrome REduction in NAvarra (RESMENA) project. Br J Nutr 2014;111:643-52, http://dx.doi. org/10.1017/S0007114513002778.

69. Raisanen JP, Silaste ML, Kesaniemi YA, Ukkola O. Increased daily sodium intake is an independent dietary indicator of the metabolic syndrome in middle-aged subjects. Ann Med. 2012;44:627-34, http://dx.doi.org/10.3109/078538 90.2011.585657.

70. Nichols GA, Moler EJ. Metabolic syndrome components are associated with future medical costs independent of cardiovascular hospitalization and incident diabetes. Metab Syndr Relat Disord. 2011;9:127-33, http://dx.doi. org/10.1089/met.2010.0105.

71. Schultz AB, Edington DW. The association between changes in metabolic syndrome and changes in cost in a workplace population. J Occup Environ Med. 2009;51:771-9, http:// dx.doi.org/10.1097/JOM.0b013e3181a88da5.

72. Milani RV, Lavie CJ. Impact of worksite wellness intervention on cardiac risk factors and one-year health care costs. Am J Cardiol. 2009;104:1389-92, http://dx.doi.org/10.1016/ j.amjcard.2009.07.007.

73. Mujica V, Urzua A, Leiva E, Diaz N, Moore-Carrasco R, Vasquez M, et al. Intervention with education and exercise reverses the metabolic syndrome in adults. J Am Soc Hypertens. 2010;4:148-53, http://dx.doi.org/10.1016/j.jash. 2010.02.008.

74. Makaryus AN, Akhrass P, McFarlane SI. Treatment of hypertension in metabolic syndrome: Implications of recent clinical trials. Curr Diab Rep. 2009;9:229-37, http://dx.doi. org/10.1007/s11892-009-0037-2.

75. Athyros VG, Kakafika AI, Papageorgiou AA, Paraskevas KI, Tziomalos K, Anagnostis P, et al. Effects of statin treatment in men and women with stable coronary heart disease: A subgroup analysis of the GREACE Study. 
Curr Med Res Opin. 2008;24:1593-9, http://dx.doi.org/10. 1185/03007990802069563.

76. Lundgren JD, Malcolm R, Binks M, O'Neil PM. Remission of metabolic syndrome following a 15-week low-calorie lifestyle change program for weight loss. Int J Obes (Lond). 2009;33:144-50, http://dx.doi.org/10.1038/ ijo.2008.225.

This work is available in Open Access model and licensed under a Creative Commons Attribution-NonCommercial 3.0 Poland License - http://creativecommons.org/ licenses/by-nc/3.0/pl/deed.en. 